\title{
Secondary Bronchiectasis due to HIV Infection in Children
}

\author{
S.Tshimanga ${ }^{1 *}$, A. Fouad ${ }^{1}$, K. Fakiri ${ }^{1}$, N. Rada ${ }^{1}$, G. Draiss ${ }^{1}$, N. Soraa ${ }^{2}$, B. Admou ${ }^{3}$, M. Bouskraoui ${ }^{1}$ \\ ${ }^{1}$ Pediatrics Department, Mohammed VI University Hospital, Marrakesh, Morocco \\ ${ }^{2}$ Laboratory of bacteriology and virology, Mohammed VI Hospital, Marrakech, Morocco \\ ${ }^{3}$ Immunology Department, Mohammed VI University Hospital, Marrakesh, Morocco
}

\section{ABSTRACT}

Introduction: Bronchiectasis is defined as a permanent and irreversible dilatation of the bronchial airways. Its association with HIV infection in the pediatric population is not widely reported in the literature. The objective was to analyze the epidemiological, clinical, etiological, therapeutic and evolutionary profile of secondary bronchiectasis due to HIV infection children. We retrospectively studied 6 cases of secondary bronchiectasis due to HIV infection children collected at the pediatric ward B of the Mohammed VI University Hospital in Marrakech over a period of 7 years from January 2012 to December 2018. There was no difference between the two sexes, an average age of 61.3 months. All 6 cases had recurrent pneumonia preceding the diagnosis of bronchiectasis; in the 5 cases with CD4 T cell counts 4 had a count less than 100 cells $/ \mathrm{mm}^{3}$. The entire chest CT scan enabled us to make the diagnosis of bronchiectasis in all the patients. The management of all our patients consisted of a good hydration, a postural drainage physiotherapy, an appropriate antibiotherapy based on the germ in question, and finally an antiretroviral therapy. The clinicovirological outcome was satisfactory for all the cases, all cases had an undetectable viral load between 6-12 months of specific treatment, an improved CD4 T cell count, and no exacerbation of bronchial dilation within one year of initiation of antiretroviral therapy.

Conclusion: The association of bronchiectasis and HIV infection in children should be specially mentioned in the etiological investigation, an adequate and early management allows to improve the quality of life and the vital prognostic.

Keywords: Bronchiectasis; HIV; Infection

\section{INTRODUCTION}

Bronchiectasis is defined as a permanent and irreversible dilation of the bronchial airways $[1,2]$. The etiological investigation explores mechanical and genetic factors, systemic diseases and primary or acquired immune deficits including HIV infection whose association with bronchiectasis in the pediatric population is not widely report. Bronchiectasis is a wellrecognized and irreversible cause of chronic lung disease among HIVinfected children and adolescents [3]. Recurrent pneumonia, interstitial

\section{Vol No: 05, Issue: 01}

Received Date: February 03, 2021

Published Date: April 03, 2021

\section{*Corresponding Author}

\section{Stanislas Tshimanga}

Pediatrics Department, Mohammed VI University Hospital, Marrakesh, Morocco, Tel/Fax: +212- 524300-700

E-mail: sttshims3@gmail.com

Citation: S Tshimanga, A Fouad, K Fakiri, N Rada, G Draiss, N Soraa, et al. (2021). Secondary Bronchiectasis due to HIV Infection in Children. Mathews J HIV AIDS. 5(1):21.

Copyright: S. Tshimanga, et al. (C) (2021). This is an open-access article distributed under the terms of the Creative Commons Attribution License, which permits unrestricted use, distribution, and reproduction in any medium, provided the original author and source are credited. 
lymphoid pneumonia, Pneumocystis carinii pneumonia, and severe immunodepression are described as risk factors associated with the development of bronchiectasis in the pediatric population [4-7]. The management of all our patients of a good hydration, a postural drainage physiotherapy, an appropriate antibiotherapy based on the germ in question and finally an antiretroviral therapy. An adapted diet was also advised. Good respiratory physiotherapy has been shown to improve respiratory function $[8,9]$. We report 6 cases of bronchiectasis in children infected with HIV.

\section{CASE REPORT 1}

A 20-month-old infant with a chronic cough since the age of 9 months, recurrent respiratory infections and constitutional symptoms was found to present, on physical examination, failure to thrive, cachexia, infectious syndrome, cervical, axillary and inguinal lymphadenopathy, and difficulty breathing. The chest X-ray revealed a honeycomb appearance (Figure 1) and the thoracic CT showed diffuse cylindrical bronchiectasis.

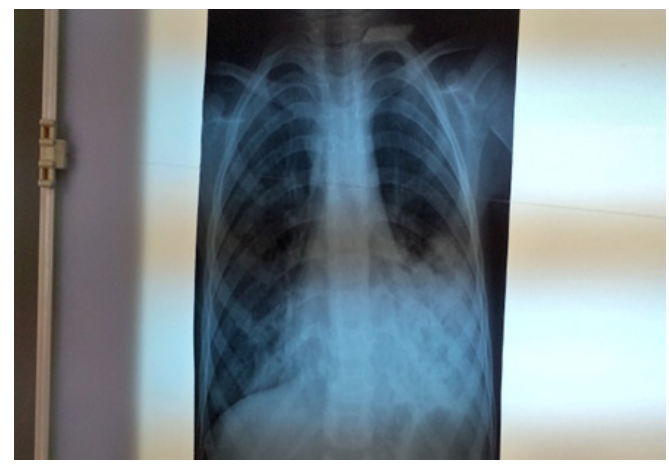

Figure 1: Chest X-ray: honeycomb appearance.

Markers of inflammation were within norms. The etiologic assessment found HIV seropositivity. Stage IV 4 HIV infection based on the WHO staging was confirmed by western blot serology. The viral load was 57638 copies / ml and CD4 T cell count was 61 cells / mm3. The patient's condition improved after initiation of a treatment comprising oxygen therapy, chest physiotherapy, antiretroviral therapy (ART) and appropriate antibiotics. The clinical and biological outcomes were characterized by abolishment of episodes of respiratory infection the year following the start of treatment, and an undetectable viral load and a CD 4 T cell count of 480 cells/ $\mathrm{mm}^{3}$.

\section{CASE REPORT 2}

A 7-year-old child, deceased father (unclear cause of death), was hospitalized for hemoptysis, a history of diarrhea and chronic cough. The physical examination found digital clubbing (Figure 2), a -3SD growth retardation, cachexia and bilateral crackling breath sounds. Chest X-ray showed bronchial syndrome and thoracic CT showed bilateral cylindrical bronchial dilation (Figure 3). The inflammatory assessment found leukopenia (3610 cells/ $\mathrm{mm}^{3}$ ), lymphopenia (1140 cells $/ \mathrm{mm}^{3}$ ) and neutropenia (1260 cells $/ \mathrm{mm}^{3}$ ); the CRP was $82.3 \mathrm{mg} / \mathrm{l}$ and the etiological investigation revealed a WHO stage IV 4 HIV infection by HIV seropositivity and quantification of viral load (314029 copies/ml); the CD4 T cell count was 02 cells $/ \mathrm{mm}^{3}$. The initiation of ARV treatment, antibiotics associated with postural drainage physiotherapy, significantly reduced the number of exacerbations with an undetectable viral load and a CD4 T cell count of 428 cells $/ \mathrm{mm}^{3}$.

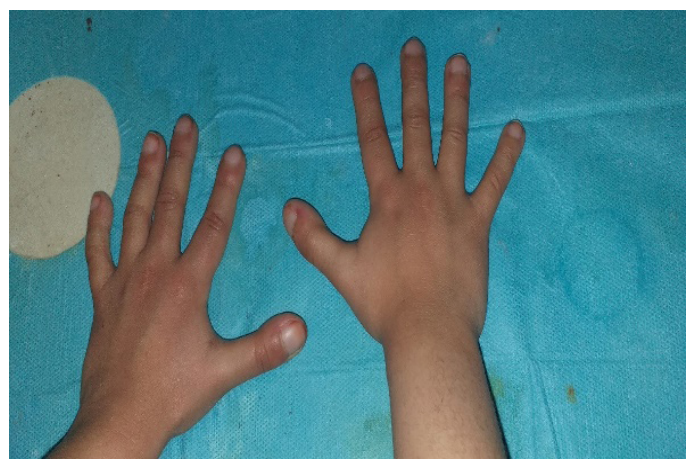

Figure 2: Digital clubbing.

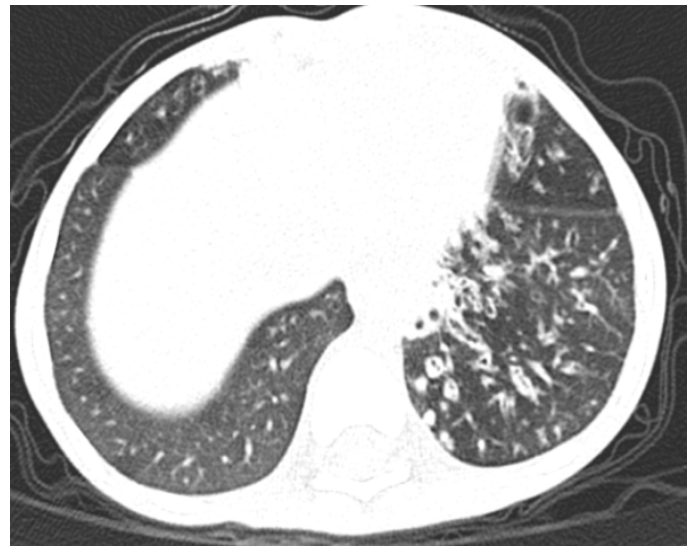

Figure 3: Thoracic CT scan: kystic bronchiectasis.

\section{CASE REPORT 3}

A 9-year-old child who was followed up for HIV infection since the age of 8 months, presented purulent bronchorrhea with a history of recurrent respiratory infections. The physical examination found febrile polypnea with bilateral crackles. Chest X-ray showed a bronchial syndrome and thoracic CT showed bilateral cylindrical and cystic bronchial dilation. The CD 4 T cell count was 48 cells $/ \mathrm{mm}^{3}$ and the HIV viral load was above 1,000,000 copies $/ \mathrm{ml}$. The etiological investigation discovered that ART was not being adhered to, and this was the basis for immuno-virological resistance. Therapeutic education and the move to second-line treatment comprising 
AZT / 3TC + LPV / r associated with appropriate antibiotics and respiratory physiotherapy curbed symptoms. Viral load was monitored and was undetectable, and CD4 T cell count was 555 cells $/ \mathrm{mm}^{3}$.

\section{CASE REPORT 4}

A 3-year-old child, whose mother was diagnosed with HIV infection going back 2 months, was admitted for prolonged unprobed fever with failure to thrive. The mother reported the occurrence of recurrent respiratory infections in the child as well as chronic diarrhea. The physical examination found weight and height at $-3 \mathrm{SD}$, a temperature of $37.8^{\circ} \mathrm{C}$, bilateral parotidomegaly, lateral cervical, axillary and inguinal lymphadenopathy and oral candidosis. Chest X-ray showed an alveolar syndrome with right lung atelectasia and thoracic CT showed bronchial dilation of the apical segment of the right upper lobe. Lab findings on inflammation revealed hyperleucocytosis of 17760 cells $/ \mathrm{mm}^{3}$, predominantly lymphocytic $\left(10580\right.$ cells $/ \mathrm{mm}^{3}$ with normochromicnormocytic anemia) while CRP was within norms. The etiological investigation found HIV-1 seropositivity, and a stage 3 WHO HIV infection was confirmed by viral load quantification: 160 copies / $\mathrm{ml}$ and the CD4 $\mathrm{T}$ cell count were not available. The remaining lab findings were without peculiarity. The treatment consisted of an antipyretic, an antibiotic, antifungal, and ART. The outcome was characterized by clinical and biological improvement after 6 months of treatment with a viral charge now undetectable, and CD 4 T cells at 744 cells $/ \mathrm{mm}^{3}$ and without recurrence of respiratory infections the year following specific treatment.

\section{CASE REPORT 5}

A child aged 3 years, hospitalized for febrile respiratory discomfort with a history of recurrent purulent otitis since the age of 7 months, followed up for suspicion of celiac disease, recurrent oral candidosis with a history of the death of a male sibling at 1 month of life in unclear circumstances. The physical examination found failure to thrive at $-3 \mathrm{SD}$ and a febrile state of $38.3^{\circ} \mathrm{C}$. The patient had signs of labored breathing (flaring of nostrils and subcostal recession) and bilateral crackling pulmonary sounds. The chest X-ray revealed a miliary appearance and thoracic CT showed cylindrical bronchial dilation of both lungs, micronodularmiliary images associated with zones of parenchymal condensation, very likely of infectious origin (Tuberculosis). HIV serology was found to be positive, and the WHO stage III 3 HIV infection was confirmed by western blot. The CD4 T cell count was 323 cells $/ \mathrm{mm}^{3}$. The search for Koch's bacillus was negative. The child was put on oxygen therapy, chest physiotherapy, antibiotics, ART. The outcome was marked by the clinical and biological improvement of the patient as well as her respiratory recuperation the year after initiation of ART, with an undetectable viral load and CD4 T cells at 573 cells $/ \mathrm{mm}^{3}$.

\section{CASE REPORT 6}

A 7-year-old child hospitalized for prolonged fever, chronic cough, with a history of repeated purulent otitis, recurrent respiratory infections, deceased mother of unknown cause, was found to present, on physical examination, cachexia, extensive molluscumcontagiosum, digital clubbing, oral candidosis, and bilateral crackling chest sounds. The chest X-ray showed a honeycomb appearance in the middle lobe on the right side, and the thoracic CT confirmed the presence of cystic and cylindrical bronchial dilation. The inflammation lab work-up revealed a leukocyte cell count of 5160 cells/ $\mathrm{mm}^{3}$, predominantly neutrophiles, with lymphopenia of 640 cells $/ \mathrm{mm}^{3}$; CRP was $234 \mathrm{mg} / \mathrm{l}$; quantiferon assay was positive and the search for Koch's bacillus in sputum was negative. The etiological investigation revealed HIV 1 seropositivity confirmed by the quantification of viral load of 463784 copies / $\mathrm{ml}$, and the CD4 $\mathrm{T}$ cell count was 24 cells $/ \mathrm{mm}^{3}$. A stage IV 4 WHO HIV infection was concluded on. The treatment consisted of anti-bacillary antibiotics, fluconazole, and ART combined with postural drainage physiotherapy. The outcome was marked by clinical and biological improvement and an undetectable viral load.

\section{DISCUSSION}

Bronchiectasis is defined as a permanent and irreversible dilation of the bronchi [2]. This is a chronic airway affection whose pathogenic mechanism is governed by Cole's "vicious circle" (Figure 4). This results in poor mucus clearance, persistent bacterial colonization, airway obstruction, inflammation and progressive tissue destruction $[2,10]$.

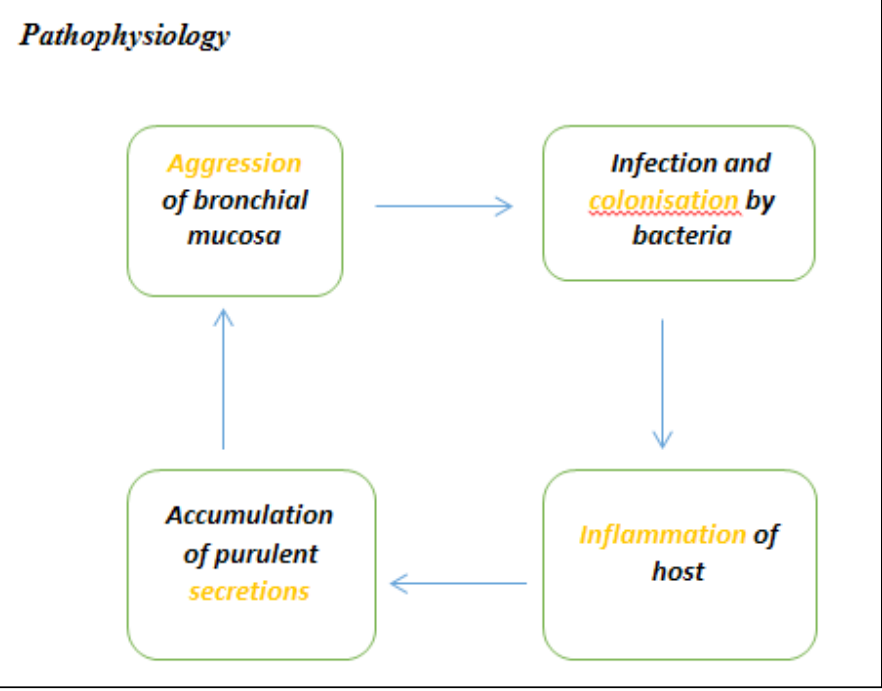

Figure 4: Cole's vicious circle. 
In children with HIV infection, alteration of bronchial defense mechanisms promotes the development of bronchial dilation by the susceptibility to infections of the bronchial walls that become damaged. In patients with AIDS, we find not only the alteration of the function of $\mathrm{T}$ lymphocytes but also, and especially, of pulmonary monocytes and macrophages $[11,12]$.

A study from the USA in the pre-ART era reported that $6 \%$ of 749 HIV-infected children without pre-existing lung disease developed radiographically or histologically determined bronchiectasis during an average of 6 years of follow-up [4].

In a retrospective case-control study of 19 HIV-infected children presenting bronchial dilation, it was shown that some four risk factors were associated with the development of bronchial dilation, viz: recurrent pneumonia, interstitial lymphoid pneumonia, Pneumocystis carinii pneumonia, and severe immunodepression [4-7]. In the same study $89 \%$ of the cases had recurrent pneumonia preceding the diagnosis of bronchiectasis as in our study. Pulmonary pathogens can trigger local inflammation, resulting in scarring and destruction of lung tissue [13].
Engi et al in a study described several risk factors associated with chronic lung disease in adolescents living with HIV including malnutrition and stunted growth. Malnutrition during the first year of life is associated with decreased lung function at 1 year of age $[14,15]$. In our study all the patients presented a picture of severe malnutrition.

Sheikh S, et al. also found in their retrospective study that almost all children who were followed for HIV infection and had bronchial dilation had a CD4 T cell count of less than 100 cells $/ \mathrm{mm}^{3}$ [16]. In our study, all cases had a history of some form of recurrent respiratory infections, and in the 5 cases with CD 4 T cell counts, 4 or $80 \%$ had a count less than 100 cells $/ \mathrm{mm}^{3}$. The only case that had a CD4 T cell count of 323 cells $/ \mathrm{mm}^{3}$ was already being followed up for pulmonary tuberculosis, which is still a public health issue in Morocco. There was no difference between the two sexes during our study. These results are superimposable to those found by Berman MD, et al [4]. The average age found by Berman MD, et al. and Sheikh $\mathrm{S}$, et al. was 112 months. In our study we found an average age of 61.3 months (Table 1 ). The difference could be related to the small size of our sample $[4,17]$.

\begin{tabular}{|c|c|c|c|c|}
\hline & \multirow{2}{*}{ Mean } & \multirow{2}{*}{ Median } & \multicolumn{2}{|c|}{ Extreme values } \\
\cline { 3 - 4 } & & & Min & 108 \\
\hline Age & 61.3 & 60 & 20 & $>1000000$ \\
\hline First viral load & 367122.2 & 314029 & 106 & 323 \\
\hline First CD4 & 91.6 & 48 & 428 & 744 \\
\hline Course of CD4 & 556 & 555 & 02 & Max \\
\hline
\end{tabular}

Table 1: Demographic, immunological and virological profiles of patients.

Only one of the 6 cases studied, being followed for HIV infection, had developed bronchial dilation as a result of poor adherence to ARV therapy. This resulted in a viral surge coupled with the profound decrease in CD4 T lymphocytes, which is one of the factors implicated in the genesis of bronchial dilation in this population [3]. In fact, in the absence of a correctly conducted treatment, there is re-emergence of wild-type viruses [18], i.e. without ARV-sensitive mutation (Figure 5).

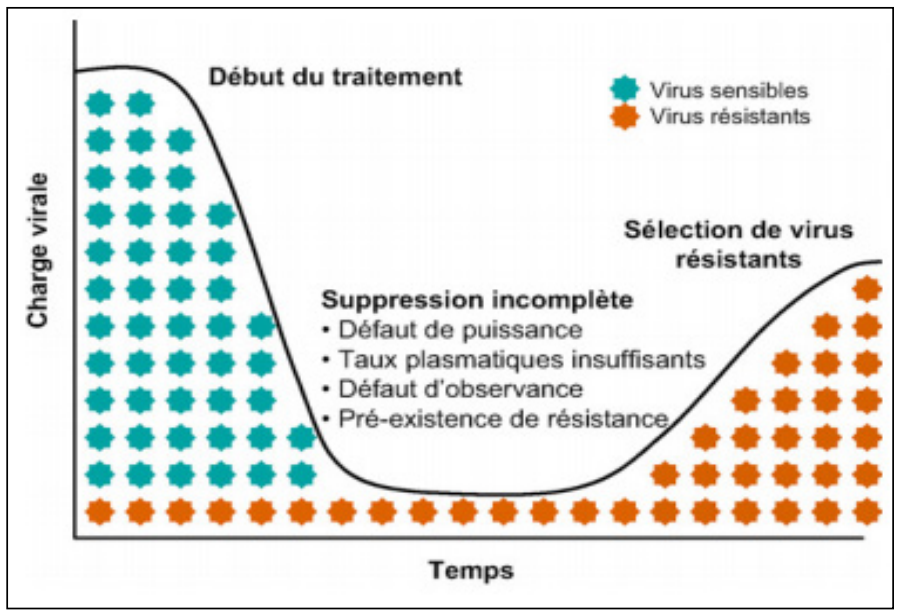

Figure 5: Mechanisms of selection of resistant viral strains during ART. 
Initially Berman MD, et al. out of 19 patients, made the diagnosis of bronchial dilation of 12 cases by standard chest X-ray, 5 cases by thoracic CT scan, and 2 cases by pathology studies [4]. In our study all patients had their diagnostic confirmation on thoracic CT. As bronchial dilation can be responsible for significant morbidity, it is important to know how to recognize it so as to guide the etiological diagnosis by means of the chest CT scan, which is the reference technique [16]. In our study all the chest CT scan enabled us to make the diagnosis of bronchiectasis in all the patients.

The management of all our patients consisted of a good hydration, a postural drainage physiotherapy, an appropriate antibiotherapy based on the germ in question, and finally an antiretroviral therapy. An adapted diet was also advised.
Good respiratory physiotherapy has been shown to improve respiratory function $[8,9]$.

The clinico-virological outcome was satisfactory for all the cases we have studied (Table 2). Indeed, all cases responded to initiated treatment and did not show bronchial dilation exacerbations within 12 months of starting treatment. On the immuno-virological level, no patient had their CD4 $\mathrm{T}$ cell count rechecked until one year after the start of treatment. This could be explained by their geographical location (most of these cases came from isolated regions located several kilometers from the Hospital), and the cost of analyses and the procedures for their being done at the Hospital were obstacles. It should be noted here that no patient required surgery.

\begin{tabular}{|c|c|c|c|c|}
\hline & \multirow[b]{2}{*}{ Clinicaloutcome } & \multicolumn{2}{|c|}{ Immuno-virological course } & \multirow{2}{*}{$\begin{array}{l}\text { Number of hospitalizations } \\
\text { for exacerbations }\end{array}$} \\
\hline & & CD4 (cells $\left./ \mathrm{mm}^{3}\right)$ & $\begin{array}{c}\text { Viral load } \\
\text { (copies/ml) }\end{array}$ & \\
\hline Case 1 & Satisfactory & 480 & undetectable & none \\
\hline Case 2 & Satisfactory & 428 & undetectable & none \\
\hline Case 3 & Satisfactory & 555 & undetectable & none \\
\hline Case 4 & Satisfactory & 744 & undetectable & none \\
\hline Case 5 & Satisfactory & 473 & undetectable & none \\
\hline Case 6 & Satisfactory & - & undetectable & none \\
\hline
\end{tabular}

All cases had an undetectable viral load between 6-12 months of specific treatment, an improved CD4 T cell count, and no exacerbation of bronchial dilation within one year of initiation of antiretroviral therapy (Table 2). The average of CD4 T lymphocytes monitored was 536 cells $/ \mathrm{mm}^{3}$ (Table 1 ).

\section{CONCLUSION}

The association of bronchial dilatation and HIV infection in children should be accorded due attention in etiological investigations in order to improve quality of life and increase chances of survival.

\section{CONFLICT OF INTEREST}

None

\section{CONSENT FOR PUBLICATION}

A written informed consent was obtained from all patients when they were enrolled.

\section{REFERENCES}

1. Brinchault G, Morel V, Meunier C, Delaval P. (2004). Dilatations des bronches. EMC Médecine. 1(2):131-40.
2. Cole PJ. (1984). A new look at the pathogenesis and management of persistent bronchial sepsis: a «vicious circle» hypothesis and its logical therapeutic connotations. In: Davies RJ, editor. Strategies in the management of chronic bronchial sepsis. Oxford: Medicine publishing Foundation. 1-20.

3. Ferrand RA, Munawa L, Matsekete J, Bandason T, Nathoo $\mathrm{K}$, et al. (2010). Undiagnosed HIV infection among adolescents seeking primary healthcare in Zimbabwe. Clin Infect Dis. 51:844-51.

4. Berman DM, Mafut D, Djovic B, Scott G, Mitchell C. (2007). Risk factors for the development of bronchiectasis in HIV-infected children. PediatrPulmonol. 42(10):871-5.

5. Scott GB, Hutto C, Makuch RW, Mastrucci MT, O'Connor T, et al. (1989). Survival in children with perinatally acquired human immunodeficiency virus type 1 infection. N Engl J Med. 321(26):1791-6.

6. Scott GB. (1991). HIV infection in children; clinical features and management. J Acquir Immune Defic Syndr. 4:109-15. 
7. Amorosa JK, Miller RW, Laraya-cuasay L, Gaur S Marone R, et al. (1992). Bronchiectasis in children with lymphocytic interstitiel pneumonia and acquired immune deficiency syndrome. Plain film and CT observations. Pediatr Radiol. 22(8):603-6.

8. Redding G, Restuccia R, Cotton EK, Brooks JG. (1982) Serial changes in pulmonary functions in children hospitalized with cystic fibrosis. Am Rev Respir Dis. 126(1): 31-6.

9. Gold R, Carpenter S, Heuter H, Corey M, Levison H. (1987). Randomized trial of ceftazidime versus placebo in the management of acute respiratory exacerbation in patients with cystic fibrosis. J Pediatr. 111(6Pt1):07-13.

10. Cole PJ. (1986). Inflammation: a two-edged sword. The model of bronchiectasis. Eur J Respir Dis Suppl. 147:6-15.

11. Reynolds HT. (1987). Host defense impairments that may lead to respiratory infections. Clin Chest Med. 8(3):339-58.

12. Beck JM, Shellito J. (1989). Effects of human immunodeficiency virus on pulmonary host defenses. Semin Respir Infect. 4(2):75-84.
13. Guillemi SA, Staples CA, Hogg JC, Le AN, Lawson ML, et al. (1996). Unexpected lung lesions in high resolution computed tomography (HRCT) among patients with advanced HIV disease. Eur Respir J. 9:33-36.

14. Engi FA, Miller RF, Ferrand RA. (2017). Bronchiectasis and other chronic lung diseases in adolescents living with HIV, Curr Opin Infect Dis. 30(1): 21-30.

15. Gray DM, Turkovic L, Willemse L, Visagie A, Vanker A, et al. (2017). Lung function in african infants in the drakenstein child health study: impact of lower respiratory tract illness. Am J Respir Crit Care Med. 195(2):212-20.

16. Sheikh S, Madiraju K, Steiner P. (1997). Bronchiectasis in pediatric AIDS. Chest. 112(5):1202-7.

17. Chassagnon G, Brun AL, Bennani S. (2018). Imagerie des dilatations des bronches. Rev Pnemol clin.

18. Delaugerre C, Chaix ML, Warszawki JC. Rouzioux C, Blanche S. (2007). La résistance du VIH-1 aux antirétroviraux chez les enfants infectés: du nouveau-né à l'adolescent. Archive de Pédiatrie. 14(3):298-302. 